\title{
Survival Analysis
}

\section{Survival from cancer of the uterus in England and Wales up to 2001}

\author{
N Cooper', MJ Quinn', B Rachet ${ }^{2}$, E Mitry ${ }^{3}$ and MP Coleman ${ }^{*, 2}$ \\ 'Social and Health Analysis and Reporting Division, Office for National Statistics (Room FG/I I 4), I Myddelton Street, London ECIR IUW, UK; \\ ${ }^{2}$ Cancer Research UK Cancer Survival Group, Non-Communicable Disease Epidemiology Unit, Department of Epidemiology and Population Health, \\ London School of Hygiene and Tropical Medicine, Keppel Street, London WCIE 7HT, UK; ${ }^{3}$ Département d'Hépatogastroentérologie et Oncologie \\ Digestive, Centre Hospitalo-Universitaire Ambroise-Paré, 9 avenue Charles de Gaulle, F-92100 Boulogne, France
}

British Journal of Cancer (2008) 99, S65-S67. doi: I0.1038/sj.bjc.660459 I www.bjcancer.com

Published online 23 September 2008

(c) 2008 Cancer Research UK

Approximately 200000 women were diagnosed with cancer of the body of the uterus around the world each year at the turn of the century. More than two-thirds of this estimated total arise in developed countries, where age-standardised incidence is four times higher than in developing countries (Ferlay et al, 2004).

In the late 1990s, there were around 5300 new cases a year of uterine cancer in England and Wales. It is the fifth most common cancer in women, accounting for $3.5 \%$ of all cases. Agestandardised incidence remained stable during the 1970s and 1980s, but it has risen by $25 \%$ since 1990 (Parkin et al, 2001; Quinn et al, 2001). Annual incidence in five deprivation groups defined by the woman's small area of residence at diagnosis ranged between 14 and 17 per 100000 per year in the late 1990 s, but there is no simple gradient across the groups, and incidence rose at a similar rate in all socioeconomic groups (data not shown). Mortality from uterine cancer has been declining steadily in all age groups except the very elderly (Quinn et al, 2001).

Women whose uterus has been removed are no longer at risk, and retaining them in the population denominators when estimating incidence rates artificially reduces the estimates. The prevalence of hysterectomy should be borne in mind when interpreting incidence rates and trends. In 1995, 2.3 million women in England and Wales had had a hysterectomy, with a peak prevalence of $21 \%$ in the age group of 55-59 years (Redburn and Murphy, 2001), so the estimated $25 \%$ rise in overall incidence since 1990 may be an underestimate of the increase.

Diagnosis of endometrial cancer may arise from postmenopausal bleeding, or irregular or heavy perimenopausal bleeding. If detected early, both endometrial carcinoma and in situ malignancy, which carries a high risk of progression to invasive cancer, are mostly curable. The mainstay of treatment is total hysterectomy, with or without removal of the ovaries, with external beam radiotherapy in some cases. Well-differentiated tumours with minimal invasion may be treated by brachytherapy with intravaginal irradiation.

\footnotetext{
*Correspondence: Professor MP Coleman;
}

E-mail: michel.coleman@|shtm.ac.uk
Endometrial cancer shares some epidemiological features with breast and ovarian cancers, such as a peak in incidence around the menopause, and risk factors such as early menarche, low parity and late menopause. The risk of uterine cancer is also increased among women treated with tamoxifen for breast cancer. The unusual pattern of human carcinogenicity of tamoxifen has been summarised as follows: 'There is sufficient evidence in humans for the carcinogenicity of tamoxifen in increasing the risk for endometrial cancer and there is conclusive evidence that tamoxifen reduces the risk for contralateral breast cancer in women with a previous diagnosis of breast cancer' (IARC, 1996).

The survival analyses reported here involve more than 53000 women aged 15-99 years who were registered with uterine cancer in England and Wales during the 14-year period 1986-1999, $87 \%$ of those who were eligible. Approximately $2 \%$ of women were excluded because their vital status was unknown on 5 November 2002 when the data were extracted for analysis; $5 \%$ because they had previously had a primary malignancy of another organ at some time since 1971, and a further $6 \%$ because their duration of survival was zero or unknown. The proportion excluded for zero or unknown duration of survival was similar in all deprivation categories, and did not change during the 1990s.

Cancers of the uterus are not normally registered without sufficient information being available for the cancer registry to assign the anatomic location as either the cervix or corpus uteri, but approximately $6 \%$ of tumours diagnosed in England and Wales during 1986-1999 had been assigned a non-specific anatomic site code (ICD-9 179, ICD-10 C55: malignant neoplasm of uterus, part unspecified); these tumours were considered ineligible for analysis.

More than half the tumours (58\%) were coded as adenocarcinoma, $15 \%$ as endometrioid carcinoma, and almost $3 \%$ as leiomyosarcoma; $12 \%$ were poorly specified carcinomas.

\section{SURVIVAL TRENDS}

Relative survival at both 1 and 5 years after diagnosis rose steadily and significantly from 85 and $72 \%$, respectively, in the late 1980 s, 
Table I Trends in relative survival (\%) by time since diagnosis and calendar period of diagnosis: England and Wales, adults (I5-99 years) diagnosed during 1986-1999 and followed up to 2001

\begin{tabular}{|c|c|c|c|c|c|c|c|c|c|c|c|}
\hline $\begin{array}{l}\text { Time since } \\
\text { diagnosis }\end{array}$ & & \multicolumn{6}{|c|}{ Calendar period of diagnosis ${ }^{\mathrm{a}}$} & \multicolumn{2}{|c|}{$\begin{array}{l}\text { Average change (\%) } \\
\text { every } 5 \text { years }^{b}\end{array}$} & \multicolumn{2}{|c|}{$\begin{array}{c}\text { Prediction }{ }^{c} \text { for patients } \\
\text { diagnosed during } 2000-200\end{array}$} \\
\hline I year & Women & 84.5 & $(83.9,85.1)$ & 85.9 & $(85.3,86.4)$ & 88.1 & $(87.5,88.6)$ & $2.5 * *$ & $(1.4,3.6)$ & 89.3 & $(88.5,90.1)$ \\
\hline 5 years & Women & 72.0 & $(71.2,72.8)$ & 72.7 & $(72.0,73.5)$ & 75.8 & $(74.8,76.7)$ & $2.5 * *$ & $(0.9,4.1)$ & 76.8 & $(75.6,77.9)$ \\
\hline
\end{tabular}

$\mathrm{Cl}=$ confidence interval. ${ }^{a}$ Survival estimated with cohort or complete approach (see Rachet et al, 2008). ${ }^{\text {bMean }}$ absolute change (\%) in survival every 5 years, adjusted for deprivation (see Rachet et al, 2008). 'Survival estimated with hybrid approach (see Rachet et al, 2008). **P<0.01.

Table 2 Trends in the deprivation gap in relative survival (\%) by time since diagnosis and calendar period of diagnosis: England and Wales, adults ( $15-99$ years) diagnosed during $1986-1999$ and followed up to 2001

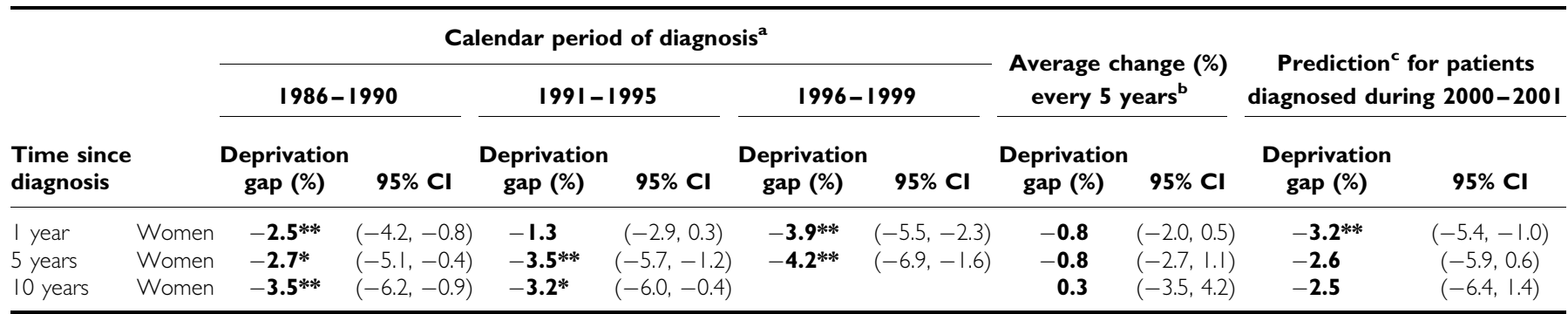

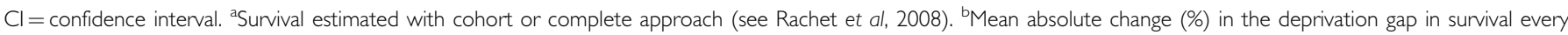
5 years, adjusted for the underlying trend in survival (see Rachet et al, 2008). ${ }^{\circ}$ Survival estimated with hybrid approach (see Rachet et al, 2008). $* P<0.05$; $* * P<0.01$.



Figure I Relative survival (\%) up to 10 years after diagnosis by calendar period of diagnosis: England and Wales, adults (15-99 years) diagnosed during 1986-1999 and followed up to 2001. Survival estimated with cohort or complete approach (1986-1990, 1991-1995, 1996-1999) or hybrid approach (2000-200I) (see Rachet et al, 2008).

to 88 and $76 \%$ in the late 1990 s. This represents a deprivationadjusted rise of $2.5 \%$ every 5 years in short-term and longer-term survival (Table 1). The increase in 5-year survival was more marked between the early and late 1990s (Figure 1).

Short-term predictions suggest that these steady upward trends are likely to continue, with predicted survival of $90 \%$ at 1 year and $77 \%$ at 5 years, based on hybrid analysis (Brenner and Rachet, 2004) of survival probabilities observed during 2000-2001 (Table 1).

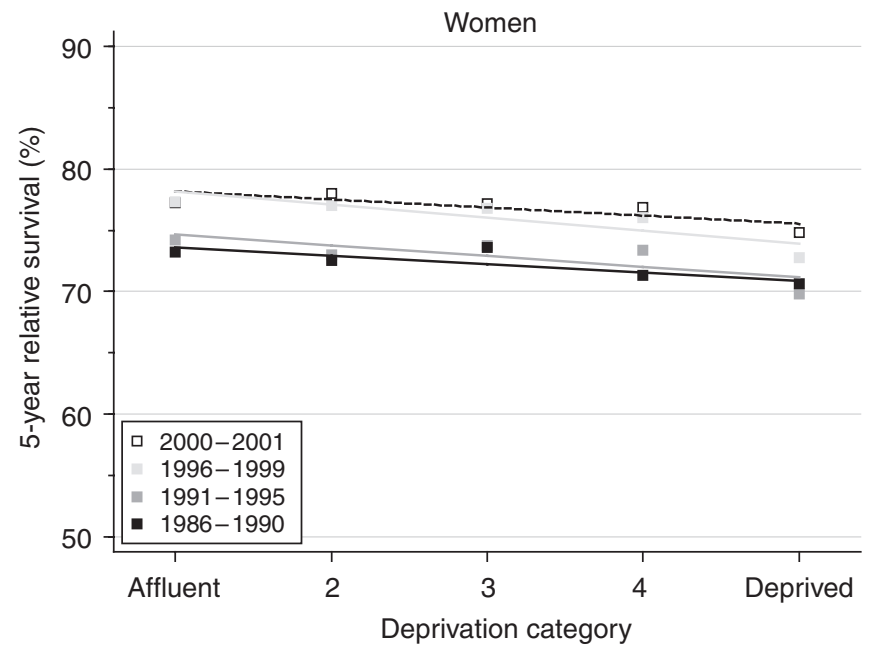

Figure 2 Trends in the deprivation gap in 5-year relative survival (\%) by calendar period of diagnosis: England and Wales, adults (15-99 years) diagnosed during 1986-1999 and followed up to 200 I.

\section{DEPRIVATION}

The deprivation gap in survival between the most affluent and the most deprived groups is approximately $4 \%$. This is a smaller gap in survival than for some other common cancers in women, but survival has nevertheless been consistently and significantly lower for women living in more deprived areas.

The deprivation gap widened slightly but not significantly from approximately $3 \%$ for women diagnosed in the late 1980 s to 
approximately $4 \%$ for those diagnosed in the late 1990s (Table 2 and Figure 2).

Predictions based on hybrid analysis of survival probabilities observed during 2000-2001 suggest that the deprivation gap for both short-term and longer-term survival is unlikely to change markedly within the next 5-10 years (Table 2).

\section{COMMENT}

Survival from uterine cancer in England and Wales is amongst the highest for any cancer in women, after melanoma of the skin, and close to that for breast cancer. Survival has improved steadily in the 15 years up to 2001, and especially during the 1990s. Although survival has improved in all socioeconomic groups, the

\section{REFERENCES}

Brenner H, Rachet B (2004) Hybrid analysis for up-to-date long-term survival rates in cancer registries with delayed recording of incident cases. Eur I Cancer 40: 2494-2501

Ferlay J, Bray F, Pisani P, Parkin DM (2004) GLOBOCAN 2002: Cancer Incidence, Mortality and Prevalence Worldwide. IARC CancerBase No. 5, version 2.0. IARCPress: Lyon. http://www-dep.iarc.fr

IARC (1996) IARC Monographs on the Evaluation of Carcinogenic Risks to Humans. Volume 66. Some Pharmaceutical Drugs. International Agency for Research on Cancer: Lyon

Parkin DM, Bray F, Devesa SS (2001) Cancer burden in the year 2000. The global picture. Eur J Cancer 37(Suppl 8): 4-66

Quinn MJ, Babb P, Brock A, Kirby L, Jones J (2001) Cancer Trends in England and Wales 1950-1999. Studies on Medical and Population Subjects No. 66. Office for National Statistics: London deprivation gap in survival between women in the most affluent and the most deprived groups has not narrowed; if anything, the data suggest that it widened slightly during the late 1990s.

Survival is closely related to stage at diagnosis, and the presenting symptom of postmenopausal bleeding in $90 \%$ of women leads to early diagnosis in the great majority. The very high survival in earlystage disease suggests that even greater attention could be given to encouraging early presentation, and to rapid referral, particularly for women in deprived socioeconomic groups.

In the early 1990s, relative survival from uterine cancer at 5 years ranged from 60 to $84 \%$ in the 22 European countries contributing to the EUROCARE-3 study. The age-adjusted European average 5 -year survival of $76 \%$ was $2-3 \%$ higher than in England and 6\% higher than in Wales (Sant et al, 2003).

Rachet B, Woods LM, Mitry E, Riga M, Cooper N, Quinn MJ, Steward J, Brenner H, Estève J, Sullivan R, Coleman MP (2008) Cancer survival in England and Wales at the end of the 20th century. $\mathrm{Br} J$ Cancer 99(Suppl 1): S2-S10

Redburn JC, Murphy MFG (2001) Hysterectomy prevalence and adjusted cervical and uterine cancer rates in England and Wales. Br J Obstet Gynaecol 108: 388-395

Sant M, Aareleid T, Berrino F, Bielska Lasota M, Carli P-M, Faivre J, Grosclaude PC, Hédelin G, Matsuda T, Møller H, Moller T, Verdecchia A, Capocaccia R, Gatta G, Micheli A, Santaquilani M, Roazzi P, Lisi D, EUROCARE Working Group (2003) EUROCARE-3: survival of cancer patients diagnosed 1990-94 - results and commentary. Ann Oncol 14(Suppl 5): $61-118$ 